\title{
The impact of rating classifications on stock prices of Brazilian companies
}

\author{
Fernanda Pagin, Matheus da Costa Gomes,
Rafael Moreira Antônio and Tabajara Pimenta Júnior
versity of São Paulo Faculty of Economics Business and Accountancy of \\ Fernanda Pagin, Matheus da Costa Gomes,
Rafael Moreira Antônio and Tabajara Pimenta Júnior
versity of São Paulo Faculty of Economics Business and Accountancy of
Ribeirão Preto, Ribeiro Preto, Brazil and \\ Fernanda Pagin, Matheus da Costa Gomes,
Rafael Moreira Antônio and Tabajara Pimenta Júnior
University of São Paulo Faculty of Economics Business and Accountancy of \\ Ribeirão Preto, Ribeirao Preto, Brazil, and \\ Luiz Eduardo Gaio \\ University of Campinas, School of Applied Science, Campinas, Brazil \\ University of Campinas, School of Apphed Science, Campinas, Brazil
}

\begin{abstract}
Purpose - This paper aims to identify if there is an impact of the rating announcements issued by the agencies on the returns of the stocks of Brazilian companies listed on Brasil Bolsa Balcão, from August 2002 to August 2018, identifying which types of announcement (upgrade, downgrade or the same initial classification) cause variations in prices around the date of disclosure of the rating.

Design/methodology/approach - The event study methodology was applied to verify the market reaction around the announcement dates in a 21 -day event window $(-10,+10)$. The market model was used to calculate the abnormal returns (ARs), and subsequently, the accumulated ARs.

Findings - The hypotheses tests allowed to verify that the accumulated ARs are different, before and after the three types of rating announcements (upgrades, downgrades and the same classification); in upgrades, the mean of accumulated ARs increases in the days before the event, while in downgrades, this increase occurs after the event. This paper concluded that the rating announcements have an impact on the return of stock of the Brazilian market and that the market reaction occurs most of the time before the event happens, which indicates that the market can anticipate the information contained in the changes in credit ratings.

Practical implications - The results have considerable implications for portfolio managers, institutional investors and traders. It facilitates investment decision-making in the face of rating classification announcements. Market participants can pay more attention to their investment strategies and asset allocation during periods of risk rating announcements. Additionally, traders can understand the form of investment strategy for superior earnings.

Originality/value - The importance of the study is related to the fact that the results may explain the causes of specific movements in the Brazilian financial market related to a source of information that may or may not be able to influence the decisions of the financial agents that operate in this market. The justification is centred on the idea that, for investors who somehow react to the announcements, it is relevant to understand the impact of rating classifications on companies, as access to such information allows for more conscious decision-making.
\end{abstract}

Keywords Credit rating, Market efficiency, Event study, Brazilian capital market, Rating announcements

Paper type Research paper

(C) Fernanda Pagin, Matheus da Costa Gomes, Rafael Moreira Antônio, Tabajara Pimenta Júnior and Luiz Eduardo Gaio. Published in Journal of Economics, Finance and Administrative Science. Published by Emerald Publishing Limited. This article is published under the Creative Commons Attribution (CC BY 4.0) licence. Anyone may reproduce, distribute, translate and create derivative works of this article (for both commercial and non-commercial purposes), subject to full attribution to the original publication and authors. The full terms of this licence maybe seen at http:// creativecommons.org/licences/by/4.0/legalcode

Received 23 August 2019 Revised 17 September 2019 Accepted 20 November 2019 


\section{Introduction}

Rating agencies are private institutions responsible for providing market opinions about the credit quality of companies or countries (Micu et al., 2006). Through a credit rating based on a series of specific and exclusive requirements of each agency, these institutions expose to the financial market their assessments according to the ability of a financial agent to pay their debts within the programmed period, and these evaluations may influence the decisionmaking process of investors and creditors (Murcia et al., 2013; Agarwal et al., 2016; Morkoetter et al., 2017).

Previous studies performed by Norden and Weber (2004), Morseth and Norgaard (2011); Galil and Soffer (2011), Freitas and Minardi (2013); Murcia et al. (2013), Finnerty et al. (2013); Bissoondoyal-Bheenick and Brooks (2015); and Kenjegaliev et al. (2016) sought to understand, directly or indirectly, whether ratings issued by the rating agencies are capable of provoking reactions in investors, interfering or not in the price of different financial assets. These studies have been developed in different parts of the world, covering completely different markets.

In Brazil, evidence of the impact of rating classifications on Brazilian company stock prices is incipient. Among the studies that have investigated the potential effects of credit ratings, Freitas and Minardi (2013) found significant impacts of the changes in the stock price of Latin American companies (Brazil, Argentina, Chile and Mexico), and the work of Murcia et al. (2013), which achieved results indicating that the ratings have information capable of causing abnormal returns (ARs) in stock prices, especially when these rating announcements involve downgrades. Another study that investigated the impact of the rating changes was developed by Antônio et al. (2018); the authors identified that there were no significant impacts on prices from the rating changes.

Considering the political-economic instability presented by Brazil in recent years and the fact that the Brazilian stock market is lean and with few participants, there is a question about how stock prices of companies listed on the Brasil Bolsa Balcão (B3) Exchange react to announcements of ratings assigned to companies, which can be expressed as follows: do rating announcements change the behaviour of the returns offered by changes in the Brazilian stock price?

The present study aims to identify if there is an impact of the rating announcements issued by the agencies on the returns of the stocks of Brazilian companies listed on B3, from August 2002 to August 2018, identifying which types of announcement (upgrade, downgrade or the same initial classification) cause variations in prices around the date of disclosure of the rating.

The importance of the study is related to the fact that the results may explain the causes of specific movements in the Brazilian financial market related to a source of information that may or may not be able to influence the decisions of the financial agents that operate in this market. The justification is centred on the idea that, for investors who somehow react to the announcements, it is relevant to understand the impact of rating classifications on companies, as access to such information allows for more conscious decision-making.

This paper differs from that of Freitas and Minardi (2013) because it deals exclusively with the Brazilian market, taking away any bias that the addition of another market could bring to the analysis of the results. This study is similar to that of Murcia et al. (2013), but the present study covers a more recent period, from August 2002 to August 2018, covering both the 2008 global financial crisis and the economic and political crisis of Brazil since 2015, as rating announcements may have greater informational relevance at times of crisis (Morseth and Norgaard, 2011). 
The results indicate that rating announcements may be a factor influencing the stock returns of Brazilian companies around the day of the announcement. The behaviour of the abnormal accumulated return variations is different for each announcement type: in upgrades, the mean accumulated ARs increase in the days before the event, while in the downgrades, this increase occurs after the event. The results seem to point to a market that anticipates the information contained in the changes in credit ratings.

In addition to this introductory section, the paper is structured as follows. The theoretical framework is found in Section 2; the methodology is developed in Section 3; the results are presented in Section 4; discussion of the results can be found in Section 5; and Section 6 contains the conclusion.

\section{Literature review}

\subsection{Rating agencies and credit rating}

Rating agencies, also known as financial rating agencies, play a fundamental role in the financial market and are responsible for assessing the risk of other companies, institutions or even countries. The evaluations of the rating agencies generate risk notes that are related to the ability of these companies and/or institutions to pay their debts within a specified time frame (Micu et al., 2006; Agarwal et al., 2016).

According to Sylla (2002) and Marandola (2016, p. 84), the emergence of the first credit rating agencies occurred in the USA in the early 20th century. Owing to the construction of the railroad system, projects existed requiring financing by local investors, but these investors did not have accurate information about the borrowers, and there was a need for a credit rating. Railway securities were, therefore, the first to earn a rating. Marandola (2016) states that over the years the credit rating business expanded, and by the 1990s almost all securities issued had a rating.

According to Marandola (2016), the rating agency industry is an oligopoly dominated by the pioneering Moody's and Standard and Poor's (S\&P), as well as Fitch Ratings. They are responsible for a market share greater than $94 \%$ of the global market, and for years they were concentrated in the USA alone. In the mid-1970s, owing to the growing number of international investors, there was a need to standardize credibility, causing these agencies to grow their international presence and establish themselves in more than 40 countries.

"Rating agencies provide an opinion on an issuer's ability to meet its financial obligations" (Micu et al., 2006, p. 1). This opinion translates into a credit rating, which is intended to facilitate comparisons between different issuers. Although large agencies have their own risk rating characteristics, there are standardized categories of risk according to their correspondence, and the market understands these rankings. As an example, Moody's "Aaa" top rating is usually equivalent to "AAA" of S\&P and Fitch Ratings. Therefore, a credit rating is not necessarily a measure of default risk, but an opinion.

\subsection{Ratings and the behaviour of prices of financial assets: empirical evidence}

Studies carried out in different markets and with distinct financial assets have brought important contributions to the understanding of the behaviour of asset prices and their relation to credit ratings, mainly supported by the market efficiency hypothesis, that prices must fully reflect any relevant information available at any time (Fama, 1970).

According to Norden and Weber (2004), any financial market that is related to credit risk (stocks, securities and derivatives) should have a rapid reaction when credit ratings bring new information. These authors developed an event study from 2000 to 2002 to verify if and how strongly the credit default swap (CDS) market responds to rating announcements. The data collected consisted of full market CDS spreads, corresponding stock prices and credit 
rating data. The zero day of the event corresponded to the day on which a certain type of rating event would occur, the event window is defined as 90 days before and 90 days after the event $(-90,+90)$. The mean abnormal stock returns and the adjusted mean CDS spread changes were calculated for each agency and event type separately, at all event time intervals, through adjustment of the stock index and the market model adjusted by the stock return.

Norden and Weber (2004) showed that (i) both in the stock market and in the CDS market, there is an anticipation of the downgrades and revision of these classifications issued by the agencies; (ii) when combined analysis of different rating events in the agencies themselves or between two of them, the downgrade announcements issued by S\&P's and Moody's are more significant in the two markets; (iii) abnormal performances are influenced by past rating levels and previous rating events in both markets, and in the case of CDS, there is also an influence of the mean pre-event rating of all agencies. In a study conducted in emerging markets, Ismailescu and Kazemi (2010) concluded that positive events had a greater impact on the CDS markets two days after the event. Besides, CDS markets anticipate negative events.

Galil and Soffer (2011) mention that among the methodological challenges encountered in the different studies on the market reactions to the announcements published by the rating agencies, the difficulty in differentiating the market responses to the different sources of information such as the ratings themselves, public media news and private information is highlighted. These authors suggest the idea that abnormal market behaviour based on a rating announcement should not be linked to that announcement only, as rating disclosures by specialized agencies may be contaminated by other information exposed simultaneously, such as announcements from other agencies or related information presented in the public media.

After controlling and/or "excluding" public and private news related to the context of responses to rating announcements, also for the CDS market, Galil and Soffer (2011) found that in uncontaminated events, all types of rating announcements generate abnormal adjusted spread changes, and these changes are more relevant in the announcements that were followed by other rating actions. Also, it was possible to conclude that the market response is more severe concerning the bad news when compared to the good news.

For Finnerty et al. (2013), a rating change does not impact by itself, but it is actually the way rating agencies have changed their understandings about the risk of debt default based on public or private information, or simply through a change in credit fundamentals. Kenjegaliev et al. (2016) examined whether changes in credit ratings convey important information to the market by calculating the impact of rating announcements on the stock returns of listed companies on the Frankfurt Stock Exchange (HDAX) in the period from 2002 to 2007, and 2009 to 2015, purposely excluding the year 2008 owing to government interventions at the time of crisis, which could contaminate the data studied. The results showed that the rating changes do not cause significant changes in the stock prices of the companies analysed in the German market. The market can adjust stock prices before the rating changes are released, meaning large anticipation occurs. In parallel to this, it was also possible to observe that the reaction is more severe when it comes to downgrades in relation to upgrades.

Bissoondoyal-Bheenick and Brooks (2015) verified the possible impacts caused by the rating announcements published by S\&P's in Australia and Japan from January 1990 to June 2012. The results showed that, as in the US market, companies with a high credit rating offer a higher return than low-rated companies. The opposite would be expected - low-rated companies should offer higher returns for the risk faced by investors. As a consequence, it 
follows that the rating announcements issued involving downgrades directly reflect a significant impact on stock returns.

Morseth and Norgaard (2011) suggest that if a rating agency is empowered to provide any new information to the market, ARs related to the day of the announcement must be able to be identified. In this study, the results brought in curious conclusions about the announcements issued by rating agencies in relation to the Norwegian companies listed on the Oslo Stock Exchange. First, no significant AR was found in cases where there was a downgrade, but when considered an aggregation of all negative announcements (such as outlooks and watchlists), the situation reverses, i.e. the negative AR becomes considerable. Second, the negative effect is more pronounced in small firms; unexpected rating announcements have more severe consequences, and a change in rating between investment grade and speculative grade is more decisive in the issuer's stock price. It was also possible to conclude that negative rating announcements became more important in the Norwegian market after the 2008 credit crunch. In relation to upgrades, there is not much significance. In fact, there is the idea that other factors may determine stock prices, and the rating agency's opinion is not necessarily the only positive rating action.

According to Freitas and Minardi (2013), the rating agencies produce opinions that may characterize a possible default on the part of the issuer. These authors reported that the presence of rating agencies in Latin America grew significantly since 2004, as did the credit quality of Latin American companies. For this reason, they have developed an event study in the four largest economies in this region (Brazil, Argentina, Chile and Mexico) to examine whether the rating changes and announcements of Credit Watch have a significant impact on stock prices in the period 2000-2009.

The study conducted by Freitas and Minardi (2013) sought to measure cumulative abnormal returns (CARs) through the market-adjusted return model, which is, in fact, a simplification of the market model, and the purpose was to understand the market reactions to the information. The defined event window comprised 14 days before $(-14)$ and 30 days after $(+30)$ the date of the announcement of the rating change. The results found that credit ratings are relevant information in Latin America, especially when dealing with downgrades. Regarding upgrades and Credit Watches, the impact is less significant.

In a study performed exclusively with Brazilian data, Murcia et al. (2013) verified the effect of credit rating announcements on stock returns in Brazil between 1997 and 2011. For this, these authors used a sample of 242 companies listed on the Brazilian Stock Exchange, of which $74 \%$ were classified by S\&P's and the remaining $26 \%$ by Moody's. For the calculation of the ARs on the three announcement types (initial classification, downgrade and upgrade), they used the market model and capital asset pricing model according to three windows: $-1,+1$; $-5,+5$; and $-10,+10$. The results showed that in cases where there was a downgrade, there were negative ARs in almost all the windows tested. The above conclusion states that rating announcements have information that can cause ARs in stock prices, especially when these rating announcements involve downgrades.

There is further evidence of the impacts of rating changes on stock prices, $\mathrm{Ng}$ and Ariff (2019) reported that stock prices change with reviews of corporate ratings. Meanwhile, Choy et al. (2006) documented that downgrades have relevant information aligned with US studies, and Elayan et al. (2003) documented that in smaller markets there were also price impacts for rating upgrades. More broadly, Hu et al. (2016) highlighted that significant effects have been identified from downgrades in the USA, UK and Italy but not for other G7 countries.

Considering the importance of the presented theme, as well as the non-standardized results of different studies in this field around the world, the present work seeks to contribute and expand the knowledge related to the effects produced by the announcements 
of the rating agencies in the Brazilian stock market. Although there is already literature with a similar proposal, the differentiation is mainly because of the peculiarities of a leaner stock market, such as Brazil, and of updated data, which consider moments during and after political-economic instability.

\section{Methodology}

\subsection{Study of events}

The event study methodology is the most adequate and used to evaluate the impact of rating announcements on stock prices since according to Camargos and Barbosa (2003), an event study can be adopted for different important events capable of investor expectations, and consequently the prices of securities.

According to MacKinlay (1997), considering the data available in the financial market, an event study makes it possible to measure the effects of a specific event on the value of a company. The impacts of an event are established in security prices, hence the importance and applicability of this type of methodology. This author defined a sequence of tasks for the accomplishment of an event study that was adopted in the present study: the definition of event and window of event, definition of selection criteria, measurement of normal and ARs, definition of the estimation process and test procedure.

The event of interest ("date zero") was defined as the rating announcement by the agencies, being an upgrade, downgrade or same initial classification; the event window in which the ARs were measured corresponded to 21 days $(-10,+10)$. In a previous analysis of studies carried out in which the methodology for the study of events was adopted, it is noted that it is common for the market to respond to the event in the days before and after (Murcia et al., 2013; Freitas and Minardi, 2013), and this justifies the choice of a reduced event window.

As in the study of Murcia et al. (2013), the estimation window corresponded to the period of 120 days $(-130$ to -10$)$ before the event window $(-10,+10)$, thus avoiding overlapping of the estimation and event windows, as shown in Figure 1.

We selected the companies listed on the B3 Exchange and the choice of each one depending on the accessibility to the data needed to conduct the present study. Although the three main agencies (S\&P, Moody's and Fitch) made rating announcements of Brazilian companies, only Moody's announcements were used because of their good representation in the Brazilian market.

A total of 117 events from August 2002 to August 2018 were obtained, randomly divided into upgrades, downgrades or the same initial classification, as represented by Table 1 .

Figure 1.

Estimation and event windows
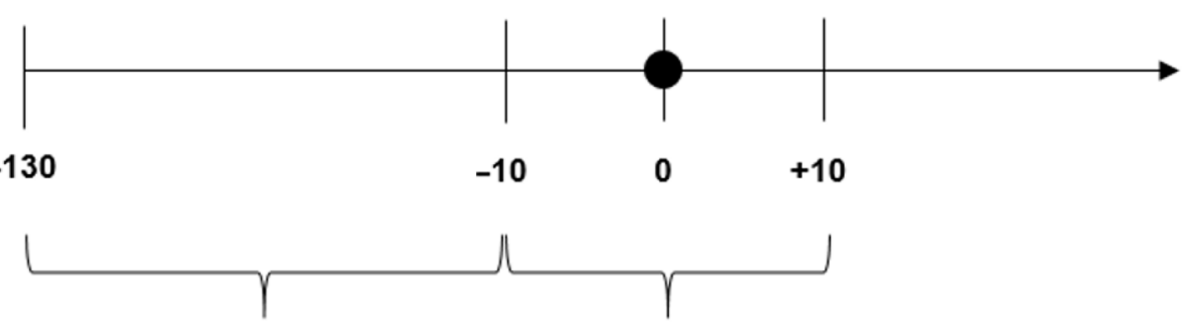

\section{Event window}

Source: Own elaboration 
These events refer to 17 different companies, with 20 being the corresponding number of stocks, independent of being ordinary or preferred. Almost all the companies consulted (94\%) make up the calculation for the Bovespa index (Ibovespa).

Stock prices of Brazilian companies

\subsection{Normal and abnormal returns}

The AR was obtained by use of the logarithmic formula, after the division between the daily quotations of the stock prices of period $t$ and period $t-1$, inferring in a continuous capitalization regime in which market information happens at all times. Thus, the rate of return is given by the following Equation (1):

$$
r=\ln \left(\frac{P t}{P t-1}\right)
$$

where $r$ is the rate of return, $P t$ is the stock price at date $t$ and $P t-1$ is the stock price at date $t-1$.

According to the need to work with a normal distribution in the parametric statistical tests, and because the logarithmic formula has a symmetric distribution, the continuous capitalization regime is the most adequate for the calculation of real returns (Soares et al., 2002).

According to Camargos and Barbosa (2003), in an event study, the measurement of the impact of the event is performed by calculating the AR. In the words of MacKinlay (1997), ARs are the observed returns in the defined event window minus the normal returns expected during the period in which they are analysed, excluding the condition that the event occurs. Thus, the AR of an asset $i$ at a date $t$ is calculated by the following formula:

$$
A R_{\text {it }}=R_{\text {it }}-E\left(R_{\text {it }}\right)
$$

where $A R_{\mathrm{it}}$ is the $\mathrm{AR}, R_{\mathrm{it}}$ is the observed return and $E\left(R_{\mathrm{it}}\right)$ is the expected return.

Luiz et al. (2008) synthesize that one of the first steps in the calculation of ARs is to obtain the expected return, being possible using the market model. According to MacKinlay (1997), this statistical model can relate the return of any financial asset with the return of a market portfolio linearly. In the present study, the portfolio is the Ibovespa. Luiz et al. (2008) complement that these returns (of the asset and the market) are related to the use of the intercept (alpha) and the coefficient of variation (beta) corresponding to the market risk, according to the following formula:

$$
R_{\mathrm{it}}=\alpha_{\mathrm{i}}+\beta_{\mathrm{i}} R_{\mathrm{mt}}+\varepsilon_{\mathrm{it}}
$$

in which $R_{\mathrm{it}}$ and $R_{\mathrm{mt}}$ are the returns of the asset and the market, respectively, $\varepsilon_{\mathrm{it}}$ is the mean zero disturbance value, and $\alpha_{i}$ and $\beta_{i}$ are the intercept and variance coefficients for asset $i$, respectively, of the market model.

\begin{tabular}{lccc}
\hline Events & Upgrades & Downgrades & Same classification \\
\hline 117 & 31 & 42 & 44 \\
$100 \%$ & $26 \%$ & $36 \%$ & $38 \%$
\end{tabular}

Source: Own elaboration
Table 1.

Number of analysed events and their classifications 
For MacKinlay (1997), to relate the return of the asset to the market return represents a potential improvement over the constant mean return model by taking into account the market conditions, and therefore, not having the reduced AR.

According to Luiz et al. (2008), the values $\alpha$ (interceptor) and $\beta$ (coefficient of variation), obtained through linear regressions, consist of ordinary least squares values. For each of the events, the linear regressions considered the stock and Ibovespa returns during the period of the corresponding estimation window.

There are relevant presuppositions that are assumed in the model used in this study: the returns of assets are not auto-correlated; the returns of the assets are correlated with a representative portfolio of the market; the coefficients $\alpha_{i}$ and $\beta_{i}$ are constant during the analysed period; the mean of the error is null; in addition to the basic assumptions required by regression analysis.

Campbell et al. (1997) believe that the market model represents an improvement in relation to the model adjusted to the mean constant, because in the market model it is possible to reduce the variance of the AR by removing the return fraction that is related to the variation of the market return, allowing a greater identification of the effects of the event, owing to the lower variability. They point out, however, that such an advantage is subject to the $R^{2}$ of the regression: the larger this indicator, the greater the reduction of the variance of the AR and, consequently, the greater the benefit.

Considering the alpha and beta coefficients calculated through the market model, it is possible to define the expected return for an asset in a given period, according to the following equation:

$$
E\left(R_{i, t}\right)=\alpha_{i}+\beta_{i} R_{\mathrm{mt}}
$$

where $E\left(R_{i, t}\right)$ is the expected return of asset $i$ in period $t, \alpha_{i}$ is the interceptor of asset $i$, $\beta_{i}$ is the coefficient of variation of asset $i$ in period $t$ and $R_{\mathrm{mt}}$ is the market return of period $t$.

Formulas (3)-(5), mentioned above, were adopted in the calculations carried out in the present study.

\subsection{Definition of the estimation process and test procedure}

In this stage of research, it is necessary to define the techniques of aggregation of the ARs and the null hypothesis. According to Camargos and Barbosa (2003), it is necessary to define a test structure in order to make possible the calculations of the ARs. These authors say that because there is no precision in determining the date the market becomes aware of the information of the event under study and how the reactions may spread over many different days, it is common to adopt the method of accumulating the ARs on these days, so that the evaluation of the price reaction is made in the time period corresponding to the event window, and this accumulation can occur through time and securities.

3.3.1 Cumulative abnormal return. The technique applied in the present study is known as CAR and consists of the simple sum of the AR in the period of the event window, and can be described by the following formula:

$$
\operatorname{CARi}(t 1, t 2)=\sum_{t=t 1}^{t 2} A R i t
$$

in which CARit is the accumulated AR, ARit is the AR and the CAR from $t 1$ to $t 2$ is in the interval $T 1<t 1 \leq t 2 \leq T 2$. 
Therefore, $C A R i(t 1, t 2)$ is the accumulated AR between the period of $t 1$ days before the event and $t 2$ days after the event. The variance of CAR can be expressed as follows:

$$
\alpha_{t}^{2}(t 1, t 2)=(t 2-t 1+1) \alpha_{\varepsilon 1}^{2}
$$

Thus, the accumulated AR (CAR) is represented as follows:

$$
\operatorname{CARi}(t 1, t 2) \sim N\left[0, \sigma_{i}^{2}(t 1, t 2)\right]
$$

Camargos and Barbosa (2003) emphasize that one cannot look at isolated cases, but it is necessary to evaluate several securities of different companies simultaneously so that the objective of the study of events - to analyse the impact of economic and financial events on the prices of securities in the capital market - be fulfilled. MacKinlay (1997) complements that it is necessary to aggregate the AR observations to the event window and through the event observations, and for this, there is the principle that there is no clustering. In this way, there is no overlap in the event windows of the selected securities. When no overlap occurs, and the assumptions of the frequency distribution are maintained, the ARs and the accumulated ARs will be independent between the securities.

Considering a sample of $N$ events, being ARt sampled from the ARs, it is possible to obtain a sample of ARs for a period $t(t 1, t 2)$ as follows:

$$
\overline{A R t}=\frac{1}{N} \sum_{i=1}^{N} A R i t
$$

With variance:

$$
\operatorname{Var}(\overline{A R t})=\frac{1}{N^{2}} \sum_{i=1}^{N} \sigma^{2} \varepsilon 1
$$

Starting from the same principle, we have the following accumulated average return:

$$
\overline{\operatorname{CARt}}(t 1, t 2)=\frac{1}{N} \sum_{i=1}^{N} \operatorname{CARi}(t 1, t 2)
$$

With variance:

$$
\operatorname{Var}\left[\overline{\operatorname{CARt}}(t 1, t 2)=\sigma^{2}(t 1, t 2)=\frac{1}{N 2} \sum_{i=1}^{N} \sigma 2 i(t 1, t 2)\right.
$$

Based on the idea that there is no clustering, and consequently, the covariance is zero, the conclusions about accumulated ARs can be obtained as follows: 


$$
\overline{C A R t}(t 1, t 2) \sim N\left[0, \sigma_{i}^{2}(t 1 . t 2)\right]
$$

3.3.2 Null and alternative hypotheses. The statistical test used in this study consists of determining the significance of the accumulated ARs by way of the null hypothesis test that the mean of these returns is equal to zero around the date of disclosure of the rating, similar to that of Murcia et al. (2013) and Freitas and Minardi (2013).

Regarding the null and alternative hypothesis, at this moment, what will be tested in the study is identified by the following hypotheses:

HO. Accumulated abnormal returns are equal before and after the release of the rating announcements.

H1. Accumulated abnormal returns are different before and after the release of the rating announcements.

\section{Results}

We obtained the results in different steps. In the first moment, the linear regressions that related the return of the assets with the returns of Ibovespa allowed to calculate the coefficients of intercept $(\alpha)$ and of variation $(\beta)$ for each event, that were applied in the market model formula to obtain the ARs for each day of the event window. The CARs before and after the event for each of the announcements were then calculated, as described in Figure 2.

Figure 2 shows that in the upgrade announcements there is a tendency to increase the mean accumulated ARs before the event, reaching a maximum of $3.2 \%$ two days before the event $(-2)$, with the difference between the extremes of this first period being 2.6 in absolute

Figure 2.

All announcements (upgrade, downgrade and same classification): CAR mean before and after the event
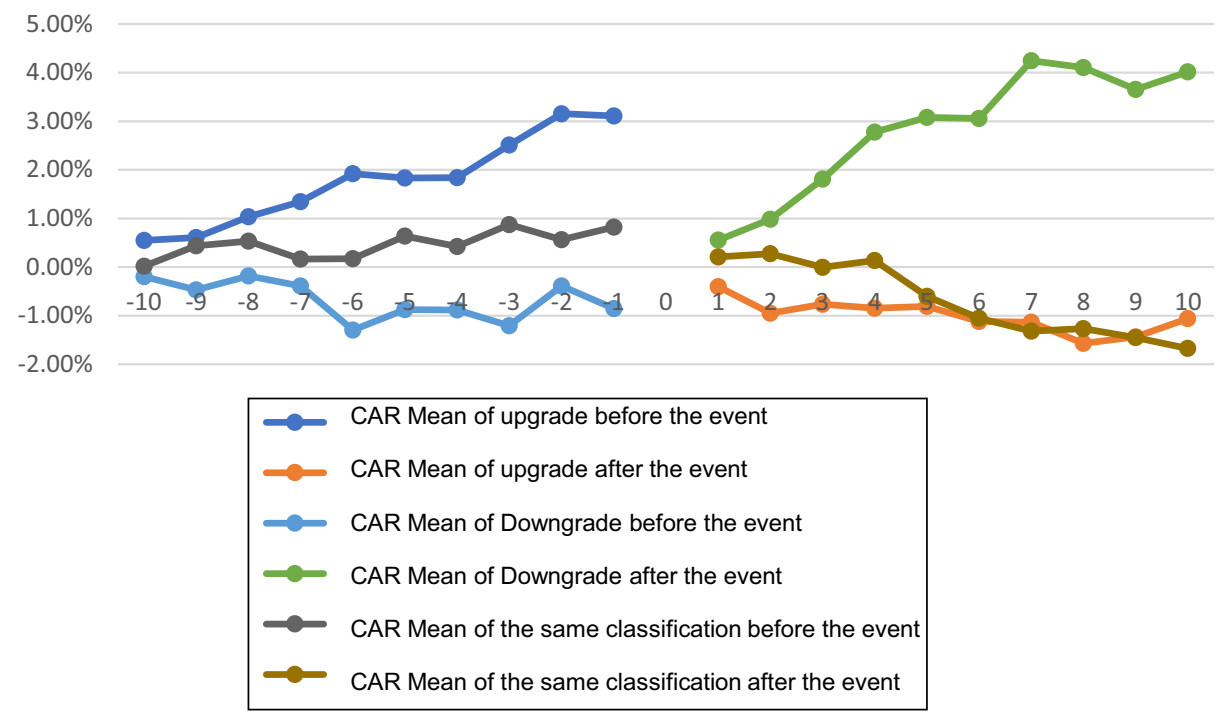

Source: Own elaboration 
terms. The mean CAR after the event is negative and fluctuates less, with a minimum point of $-1.6 \%$, and a maximum point of $0.04 \%$, the variation between the extreme points is 1.5 in absolute terms for the second period.

For the downgrade announcements, represented by Figure 2, there is an inverse behaviour of the announcements presented for the upgrades. The mean of the accumulated ARs is negative and with low oscillation during the days before the event, with the difference between the extreme points of this first period being only 1.1 in absolute terms the maximum point is $-0.18 \%$ eight days before the event $(-8)$ and the minimum point $-1.30 \%$ six days before the event $(-6)$. For the second period, after the event, we have a significant increase in the mean of the accumulated ARs, reaching a maximum of $4.2 \%$ on the seventh day after the event $(+7)$, with a 4.2 variation in absolute terms between the highest and lowest point.

For announcements with the same initial classification, as described in Figure 2, there is a small oscillation in the period before the event, with consecutive decreases and increases in the CAR mean, but remaining positive in all points. In this first period, the maximum point reached is $0.87 \%$ three days before the event $(-3)$, and the variation between the extreme points is 0.8 in absolute terms. In the post-event period, however, there was a noticeable drop in the CAR mean curve from the fourth day after the event $(+4)$ onwards, with a reduction of almost 1.6 in absolute terms until the tenth day after the event $(+10)$.

By way of Figure 2, it is possible to compare the different curves of the CAR mean before and after the event in the three announcement categories (upgrade, downgrade or same classification). The mean CARs suffered interference on the days around the event date for all announcements, and their behaviours varied depending on the announcement types. For announcements of the upgrade type, there is a more marked variation of the CAR mean in the days prior to the event, with slight fluctuations in the days after the event. In the downgrade announcements, the most striking period of variation of the CAR mean is the days after the event, with a visible increase in the curve. For announcements with the same initial rating, these variations are less noticeable and smaller in scale, with a relatively constant pattern before the event, with only one more significant fall from the fourth day after the event.

To verify whether the data follow a normal distribution, the null and alternative hypotheses to be considered in the application of the normality test were defined:

HO. The data follow a normal distribution.

H1. The data do not follow a normal distribution.

The normality test was applied in six cases for the established event window $(-10,+10)$ :

(1) first case - upgrade - before the event: the accumulated AR of -10 to -1 day for each of the 31 upgrade announcements;

(2) second case - upgrade - after the event: AR accumulated from +1 to +10 days for each of the 31 upgrade announcements;

(3) third case - downgrade - before the event: the accumulated AR of -10 to -1 day for each of the 42 downgrade announcements;

(4) fourth case - downgrade - after the event: abnormal cumulative return from +1 to +10 days for each of the 42 downgrade announcements;

(5) fifth case - same initial classification - before the event: the CAR of -10 to - 1 day for each of the 44 announcements of the same initial classification; and

(6) sixth case - same initial classification - after the event: accumulated AR from +1 to +10 days for each of the 44 announcements of the same initial classification. 
The normality test chosen was Kolmogorov-Smirnov because it was less sensitive to small deviations from a normal distribution. This test was applied through Minitab statistical software and obtained; as a result, $p$-value $>0.05$ for the periods before and after the upgrade announcement, not rejecting the null hypothesis that the data follow a normal distribution, i.e. there was insufficient evidence to conclude that the data did not follow a normal distribution. In the intervals before and after the downgrade announcements and the same initial classification, the $p$-value was below the significance level of $0.05(\alpha)$, rejecting HO. Table 2 summarizes the results of the normality tests, while Table 3 shows the hypotheses tests that were applied for each type of announcement as well as the $p$-value and the corresponding results, showing whether there was a rejection of the null hypothesis.

For the upgrade announcements, which were normal, the paired Student's $t$-test was used. For the downgrade and the same initial classification announcements, which did not present normal distribution, we chose to use the non-parametric Mann-Whitney test, and in both tests, a 95\% confidence index was considered. The CAR numbers before and after the event, which were used to apply the hypothesis tests, are segregated event by event in the Appendix.

The application of the paired $t$-test for the CAR before and after the 31 upgrade announcements brought a $p$-value $=0.018$, i.e. lower than the significance level of 0.05 , rejecting the null hypothesis. With this, it can be inferred that there is a difference between the means of the ARs accumulated before and after the event when this event is an upgrade announcement.

The Mann-Whitney test was applied twice, one for downgrades and one for announcements with the same initial rating. In the case of downgrades, the CARs before and after the 42 announcements of this classification were considered. The $p$-value found of 0.001 is less than the alpha of 0.05 and therefore rejects the null hypothesis that the CAR is equal before and after the downgrade announcements. It is possible to conclude that the difference between the medians is statistically significant and, with a confidence index of $95.04 \%$ achieved, to affirm that the median of the CAR after the event is probably higher than before

Table 2.

Synthesis of normality tests

\begin{tabular}{lll}
\hline Announcement & Value tested & Result \\
\hline Upgrade & CAR prior to the event & Do not reject $H O$ \\
Upgrade & CAR after the event & Do not reject $H O$ \\
Downgrade & CAR prior to the event & Rejects $H O$ \\
Downgrade & CAR after the event & Rejects $H O$ \\
Same classification & CAR prior to the event & Rejects $H O$ \\
Same classification & CAR after the event & Rejects $H O$ \\
Source: Own elaboration & & \\
\hline
\end{tabular}

\begin{tabular}{lllll}
\cline { 2 - 4 } & Announcement & Test & $P$-value & Result \\
\cline { 2 - 5 } & Upgrade & Student paired & 0.018 & Rejects HO \\
Table 3. & Downgrade & Mann-Whitney & 0.001 & Rejects HO \\
Synthesis of & Same classification & Mann-Whitney & 0.019 & Rejects HO \\
hypotheses tests & Source: Own elaboration & & & \\
\hline
\end{tabular}


the event. In cases in which the same initial classification was applied, the accumulated ARs before and after the 44 such announcements were considered. With $p$-value $=0.019$, one should reject the null hypothesis that CAR is equal before and after announcements of the same classification. With a confidence index of $95.06 \%$, it can be said that the CAR median before the event is supposed to be higher than after the event. The accumulated ARs before and after the events are segregated by event in the Appendix.

\section{Discussion}

Considering the hypothesis tests performed for the different categories of rating announcements and the mean accumulated ARs described by the graphs, it is possible to show that the rating announcements may be a factor influencing the stock returns of Brazilian companies around the day of the announcement. It is observed that the behaviour of the variations of these ARs is related to the type of announcements published: in upgrades, the mean of accumulated ARs increases in the days before the event, whereas in downgrades, this increase occurs after the event. For announcements with the same classification, the CAR mean has a small growth prior to the event and subsequently declines, becoming negative from the fifth day after the event $(+5)$.

The results of the three hypothesis tests carried out reject the null hypothesis that the accumulated ARs are equal before and after the event, i.e. there is a behaviour change that apparently can be explained by the event. For announcements of downgrades, according to the confidence index reached, it can be said that the post-event CAR median is greater than the pre-event CAR median, that is, the percentages that make up the CAR before the event tend to be larger. For the announcements of the same classification the reverse occurs, with the CAR median before the event being probably higher than after.

The expected logic is that good news, i.e. an upgrade, produces an increase in abnormal positive returns, while bad news or downgrade generates growth of negative ARs (Norden and Weber, 2004; Murcia et al., 2013; Kenjegaliev et al., 2016). However, the results found in the present study showed in the first moment an opposite behaviour: after the event, there was a decrease in the CAR mean for upgrade announcements and an increase in the mean for downgrade announcements. At the same time, when analysing the days before the event, we can see a significant increase in the CAR mean for announcements of upgrades, while for the announcements of downgrades the mean fluctuates a little, always remaining negative as expected. The Brazilian stock market can respond to these announcements before they actually happen.

The results found are in line with some previous studies that were presented in theoretical topics. As observed in the study by Norden and Weber (2004), which resulted in the fact that the stock markets and CDS anticipate the downgrades, the same happened in the verified events of the present study, both for downgrades and upgrades. Also, we highlight the evidence found by the present study that rating announcements carry information capable of causing ARs in stock prices, as was demonstrated in the Brazilian study of Murcia et al. (2013). This coherence can be seen jointly in the research conducted by Freitas and Minardi (2013) for the Latin American market.

Finally, the study by Kenjegaliev et al. (2016) on the German market brought an idea that is also verified in the results found in this study: the markets surveyed (Brazilian and German) undergo changes in prices before changes are disclosed. This study in Germany concluded that the rating changes are not capable of causing significant changes in the stock prices of companies listed on the Frankfurt Stock Exchange. For the case of Brazil, the evidence indicates that these rating alterations cause changes, but it is not possible to affirm how expressive they are. 


\section{Conclusion}

The purpose of this study was to verify the impact of the disclosure of rating announcements on the return of Brazilian market stocks. From the methodology of an event study with a window of events of 21 days $(-10,+10)$, the reaction of the market around the dates of the announcements was verified. The results allowed us to verify that the CARs are different, before and after the three types of rating announcements (upgrades, downgrades and the same classification). In upgrades, the mean of CARs increases in the days before the event, whereas in downgrades, this increase occurs after the event. We concluded from this that the rating announcements have an impact on the return of Brazilian market stocks and that the market reaction occurs most of the time before the event happens, so it seems that the market anticipates the information changes in credit ratings. The results were obtained from 117 events, with 31 upgrades, 42 downgrades and 44 same classifications between August 2002 and August 2018. The results of this study are limited to the period analysed, the Brazilian context and the limited number of events, as changes in the ratings of domestic companies do not occur frequently.

The results have considerable implications for portfolio managers, institutional investors and traders. It facilitates investment decision-making in the face of rating classification announcements. Market participants can pay more attention to their investment strategies and asset allocation during periods of risk rating announcements. Additionally, traders can understand the form of investment strategy for superior earnings.

\section{References}

Agarwal, S., Chen, V.Y.S. and Zhang, W. (2016), "The information value of credit rating action reports: a textual analysis", Management Science, Vol. 62 No. 8, pp. 2218-2240.

Antônio, R.M., Sticca, R.M. and Ambrozini, M.A. (2018), "Quais eventos corporativos influenciam os retornos das ações? Um estudo baseado em bootstrap”, Revista Universo Contábil, Vol. 1, pp. $28-45$.

Bissoondoyal-Bheenick, E. and Brooks, R. (2015), "The credit risk-return puzzle: impact of credit rating announcements in Australia and Japan", Pacific-Basin Finance Journal, Vol. 35, pp. 37-55.

Camargos, M.A. and Barbosa, F.V. (2003), "Estudos de evento: teoria e operacionalização", Caderno de Pesquisas em Administração, Vol. 10 No. 3, pp. 1-20.

Campbell, J.Y., Lo, A.W. and Mackinlay, A. (1997), The Econometric of Financial Markets, Princeton University, Princeton, NJ.

Choy, E., Gray, S. and Ragunathan, V. (2006), "Effect of credit rating changes on Australian stock returns", Accounting and Finance, Vol. 46 No. 5, pp. 755-769.

Elayan, F.A., Hsu, W.H. and Meyer, T.O. (2003), "The informational content of credit rating announcements for share prices in a small market", Journal of Economics and Finance, Vol. 27 No. 3, pp. 337-356.

Fama, E.F. (1970), "Efficient capital markets: a review of theory and empirical work", The Journal of Finance, Vol. 25 No. 2, pp. 383-417.

Finnerty, J.D., Miller, C.D. and Chen, R.R. (2013), “The impact of credit rating announcements on credit default swap spreads", Journal of Banking and Finance, Vol. 37 No. 6, pp. 2011-2030.

Freitas, A.P.N. and Minardi, A.M.A.F. (2013), "The impact of credit rating changes in Latin America stock markets", BAR-Brazilian Administration Review, Vol. 10 No. 4, pp. 439-461.

Galil, K. and Soffer, G. (2011), "Good news, bad news and rating announcements: an empirical investigation", Journal of Banking and Finance, Vol. 35 No. 11, pp. 3101-3119.

Hu, H., Kaspereit, T. and Prokop, J. (2016), "The information content of issuer rating changes: evidence for the G7 stock markets", International Review of Financial Analysis, Vol. 47, pp. 99-108. 
Ismailescu, I. and Kazemi, H. (2010), "The reaction of emerging market credit default swap spreads to sovereign credit rating changes", Journal of Banking and Finance, Vol. 34 No. 12, pp. 2861-2873.

Kenjegaliev, A., Duygun, M. and Mamedshakhova, D. (2016), "Do rating grades convey important information: German evidence?”, Economic Modelling, Vol. 53, pp. 334-344.

Stock prices of Brazilian companies

Luiz, I.G., Nascimento, M. and Pereira, L.C.S. (2008), "Impacto do gerenciamento de resultados no retorno anormal: estudo empírico dos resultados das empresas listadas na Bolsa de Valores de São Paulo - BOVESPA", Congresso USP de Controladoria e Contabilidade, 8, São Paulo.

Mackinlay, A.C. (1997), "Event studies in economics and finance", Journal of Economic Literature, Vol. 35 No. 1, pp. 13-39.

Marandola, G. (2016), "InkLocal credit rating agencies: a new dataset", Research in International Business and Finance, Vol. 38, pp. 83-103.

Micu, M., Remolona, E.M. and Wooldridge, P.D. (2006), "The price impact of rating announcements: which announcements matter?”, Working paper, Bank for International Settlements.

Morkoetter, S., Stebler, R. and Westerfeld, S. (2017), "Competition in the credit rating industry: benefits for investors and issuers", Journal of Banking and Finance, Vol. 75, pp. 235-257.

Morseth, K. and Norgaard, P. (2011), "The impact of credit rating announcements on Norwegian equities: an event study on Oslo Stock Exchange", Thesis, NHH Escola Norueguesa de Economia, Bergen.

Murcia, F.C.S., Murcia, F.D. and Borba, J.A. (2013), "The informational content of credit ratings in Brazil: an event study", Revista Brasileira de Finanças (Online), Vol. 11 No. 4, pp. 503-526.

$\mathrm{Ng}, \mathrm{A}$. and Ariff, M. (2019), "Does credit rating revision affect the price of a special class of common stock?”, Borsa Istanbul Review, Vol. 19 No. 1, pp. 44-55.

Norden, L. and Weber, M. (2004), "Informational efficiency of credit default swap and stock market: the impact of credit rating announcements", Journal of Banking and Finance, Vol. 38, pp. 2813-2843.

Soares, R.O., Rostagno, L.M. and Soares, K.T.C. (2002), "Estudo de evento: o método e as formas de cálculo do retorno anormal”, Encontro Nacional Dos Programas de Pós Graduação em Administração, XXVI, ANPAD, Salvador, p. 14.

Sylla, R. (2002), "Financial systems and economic modernization", The Journal of Economic History, Vol. 62 No. 02, pp. 277-292.

Corresponding author

Luiz Eduardo Gaio can be contacted at: luiz.gaio@ymail.com

For instructions on how to order reprints of this article, please visit our website:

www.emeraldgrouppublishing.com/licensing/reprints.htm

Or contact us for further details: permissions@emeraldinsight.com 